\title{
LA PERESTROIKA
}

DE LA

LITERATURA RUSA

EN EL PERÍODO

DE GLASNOST*

Nadeszda Markova**

$\mathbb{H}_{\text {n este artículo se presenta una ca- }}$ racterística general de las principales corrientes de la literatura rusa contemporánea: la prosa de la "nueva ola", la "otra" prosa y las obras de los escritores que en cierta forma se vinculan con el underground.

Así, por ejemplo, a los autores de la "otra" prosa les vincula lo que es la prosa de los "informales" de ayer. Los rasgos comunes de la "otra" prosa son la "rebeldía" y la oposición a lo que le parecía oficial. De ahí se desprende su carácter de adolescente difícil, su extravagancia y la dificultad de su diálogo con el lector educado en otros modelos literarios.

Hoy en día, en toda la literatura rusa impresa se está dando un "cambio de lenguaje", ahora el escritor puede hablar libremente sobre cualquier cosa. En este aspecto, el artículo trata el tema de la libertad interior del escritor.

El sólo hincapié en "la resistencia" y en el comentario irónico de la realidad pierde su encanto. Sólo las obras que tienen un contenido positivo y transformador pueden vivir y desarrollarse en el nuevo espacio literario.

* Traducción de Mijail Málishev.

** Filóloga rusa. 
Nadeszda Markova

\section{¿Qué es la literatura rusa de la época de glasnost?}

Felizmente responder a esta pregunta es difícil. Felizmente porque, en el período anterior, la respuesta a la pregunta iqué es la literatura contemporánea? se reducía a un listado conocido con algunos nombres como Iskander, Bitov, Makanin y algunos escritores "costumbristas". 1 La tendencia general, las directrices estilísticas no se revelaban y ahora no se revelan, aunque por razones diferentes. Si antes no tenía sentido hablar sobre el carácter general de la literatura impresa, ahora no hay posibilidades.

Por supuesto que la literatura soviética nunca fue monolítica, sin embargo daba la impresión de ser algo mediocre y estático. Parecía que todo lo interesante y lo vivo se había ido a Occidente o había brotado allá. Ahora queda claro que el estancamiento existió sólo en la superficie, que el pseudomonolito fácilmente se desintegró. Transformándose en multitud de partes, la literatura en Rusia adquirió diversidad, complejidad y contradictoriedad, que son condiciones necesarias para el desarrollo normal de la cultura.

60 Como antes, la tendencia más popular en la literatura contemporánea sigue siendo la corriente social. La vanguardia de la prosa de nuestros días se encabeza por quienes desenmascaran, y no hay ninguna razón de suponer que esta situación podrá cambiarse en un futuro cercano. A la literatura del pathos social le acompaña el éxito permanente.

El enfoque puramente estético hacia la literatura siempre ha sido y será destino de la minoría. La cuestión consiste en si va a existir o no esta minoría. Más concretamente ¿queda o no para ésta papel, tinta tipográfica y espacios en libros y revistas?

Ahora tal mínimo de papel, tinta y espacio empieza a otorgarse a esta corriente, digamos, estética. El fenómeno más importante del período de glasnost es, quizás, la salida masiva a la superficie de la literatura "pura".

1 "costumbristas" refiere a quienes escriben sobre el mundo y las tradiciones campesinas. 
El fenómeno todavía no está consolidado ni en el aspecto organizativo (que es natural, porque el proceso de escribir es profundamente individualista) ni en el estilístico, ni en el de género. Precisamente por eso, uno se ve obligado a reunir autores y libros diversos con el único criterio de ausencia de servilismo político y de didáctica moralista en sus obras. Por esta misma razón, es imposible dar nombre a la corriente porque, propiamente hablando, aún no existe.

Vamos a utilizar entonces un término usado frecuentemente, la "nueva ola", conformándonos el hecho de que esto es en realidad una ola, dado que hay muchos escritores de este tipo y porque esta ola realmente es nueva, ya que antes no había salido a la superficie de la literatura soviética impresa.

Esta corriente tiene una actitud escéptica hacia los ideales sociales, actitud elaborada no sólo de modo abstracto, sino a menudo basándose en experiencias concretas, puesto que sus protagonistas antes ocuparon cargos socialmente pasivos: veladores, guardianes de costas, elevadoristas, trabajadores de limpieza, etc. Propiamente hablando, se puede considerar que el rasgo distintivo de la "nueva ola" es el escepticismo en cuanto a la posibilidad del ideal social.

Trataremos de destacar los rasgos principales de la prosa de la "nueva ola". Para ella el medio ambiente no tiene ninguna importancia. No tiene ninguna significación la pertenencia social de los personajes: pueden ser obreros, campesinos o intelectuales. El rasgo esencial de esta prosa es la actitud de autenticidad del autor. El personaje más auténtico para el autor es él mismo. Para él tiene más importancia la característica artística que la social.

Además, el escritor puede representarse en diferentes papeles detrás de los cuales, no obstante, claramente se le adivina. Frecuentemente el autor no oculta esta situación, al poner en primer plano precisamente los talentos artísticos del personaje preferido.

Los personajes - escritores- se inclinan, como les es propio a los escritores, al estilo aforístico. Ellos de buena gana recurren a las fórmulas, pero de hecho resulta que estas fórmulas metafísicas son antifórmulas, es decir, no están orientadas a ser guías de la vida, sino que son parodias.

El medio principal de realización de esta "parodia metafísica" es la ironía. La "nueva ola" es totalmente irónica. 
La ironía destructora y la misericordia equilibradora, este sumar y restar en la prosa dio un grado nulo al estilo. La vida es trágica porque se acaba con la muerte. Todo se realiza dentro y el resto, el régimen político, las relaciones sociales, la vida cotidiana, es sólo lo secundario y lo accesorio. Tal concepción del mundo está en el fundamento de la obra de la pléyade de literatos aparecidos en los últimos tiempos.

La actitud irónica en la literatura es universal, como en el romanticismo, que no hace diferencia entre lo real y lo fantástico. Los escritores de la "nueva ola", aunque no deliberadamente, recurren a la mística, al misterio o a lo fantástico; confían incondicionalmente en el detalle inanimado, en el apoyo de algo real y auténtico.

La duración de términos como: "la literatura underground", "la nueva ola" y "la nueva prosa juvenil" resultó inesperadamente corto. Los vínculos creativos que paulatinamente se han establecido entre "los escritores nuevos" y las corrientes y escuelas establecidas (o que existieron anteriormente), por lo visto son más fuertes y más importantes que las relaciones que unen a estos escritores con la corriente "underground." No tiene sentido poner en la misma línea, digamos, la virtuosa y traviesa prosa de Valeria Nárbikova y la escritura austera de cariz filosófico y psicológico de Leonid Borodin. Y, no obstante, existen 62 cuestiones oportunas de tratar si unimos en nuestro análisis a los nuevos escritores. Por lo menos hay una, y esta cuestión es la libertad interior del artista. Pero, ¿es posible plantear este problema ante escritores para quienes el principio más importante, creativo y vital que predeterminó en muchos aspectos sus propios destinos fue justamente la libertad de expresión? Propiamente hablando (por definición) esta literatura es la de los escritores que se negaron a trabajar en aquel espacio estético e ideológico que les fue concedido oficialmente; es la literatura - aprovechemos la nueva jerga romántica-creada en "las estaciones de calefacción" de Moscú, Leningrado y Sverdlovsk. Es también la prosa de aquellos que llevaron a Occidente el talento no desarrollado en su patria y que publicaron en las revistas Grani o Kontinent, accesibles a un círculo muy estrecho de lectores. En esencia, esta escritura es también una variante de la "prosa de estación de calefacción".

$\mathrm{Al}$ arte le da lo mismo cuáles sean las relaciones entre la historia y tu suerte individual, cuál es el pleito entre tú y tu época. Por poderoso que sea el temperamento civil del artista, por noble y útil que le parezca su 
actividad en la esfera de la vida social, a él le conviene hablar no sólo en nombre de su tiempo, sino en el de todos los tiempos. Pues una de las funciones principales del arte es la concreción y la transmisión a la sociedad de los valores engendrados por la vida, el tesoro espiritual de decenios de generaciones.

El "artista libre" es un concepto complicado y contradictorio, que implica tanto la libertad como la esclavitud, a aquél que entiende que debe someter su obra a una causa más importante que él mismo, como al que sólo obedece a su vocación literaria y no a alguien o algo externo.

Eduard Limonov, quien vive en París y ha obtenido fama europea, se considera a sí mismo como un artista absolutamente libre. Su última novela Hemos tenido la Gran Época fue publicada simultáneamente en Moscú y en París.

En apariencia es un libro bastante tradicional para la literatura rusa; una narración sobre la infancia en la posguerra: madre, padre, el apartamento para varias familias en Jarkov, parientes, coetáneos, el círculo de intereses familiares, etc. Su prosa tiene un encanto particular a consecuencia de su expresión libre, de alguna manera antojadiza.

Se trata de una novela sobre la infancia, cuya narración da la impresión de ser abierta e ingenua, estimulando al lector a sus propios recuerdos, a la sumersión en un mundo casi desaparecido. Pero esta vez la sumersión no se logra; el mundo que surge bajo la pluma de Limonov tiene una extraña impenetrabilidad, que se esclarece más tarde: en este mundo falta el espacio para la vida del hombre concreto. La narración se asemeja a una acotación muy dilatada de una pieza que no puede iniciarse. El autor no se desvía del tono un tanto irónico hasta cuando relata las cosas más íntimas y cordiales; es una impasibilidad y un extrañamiento raro, a pesar de la presencia de todos los atributos de la narración emocionada y lírica.

La otra extrañeza de esta prosa es el carácter detallado en la descripción de aquellas señales del tiempo que son bien conocidas por el lector. Digamos, por ejemplo, para qué es necesario explicar tan detalladamente qué cosa es el capote ruso o el barajolka. ${ }^{2} \mathrm{O}$, también, para qué demostrarnos que el peso principal de la última guerra mundial cayó sobre los

${ }^{2}$ Tipo de mercado posterior a la Revolución. 
Nadeszda Markova

hombros de los rusos y no en los de los ingleses o de los norteamericanos. Esto parece extraño mientras no se comprenda que la novela está dirigida al lector occidental, para quien la vida cotidiana de los hombres soviéticos es absolutamente fantasmagórica y oscura. Con seguridad, es por eso que el autor explica frecuentemente la realidad de la vida rusa a través de sus análogos occidentales. Por ejemplo, la atmósfera de una velada en el círculo artístico de las fuerzas armadas se compara con la del club nocturno Crazy Horse Saloon o con Rasputín. Otro ejemplo es la imagen de un inválido: "... busto sobre carretones; los primeros patinadores en el mundo fueron los inválidos soviéticos sin piernas”, etc.

La orientación hacia la percepción de su lector occidental repercute en el tono de la narración de Limonov. La manera en que el autor escribe sobre la guerra es extrañamente ligera e inusual. Como si para él no existiera el sonido trágico de este tema, que todavía es inherente al clima espiritual de nuestra sociedad y que de cierta forma tiñe el trato de nuestra literatura con esta época. Con la guerra el autor está "a corta distancia": "las pasiones del abuelo le llevaron al campo de batalla cerca de Leningrado. Y él pereció en el campo roturado muy profundamente por la artillería alemana; dicen que este campo de batalla fue despedazado más profundamente que el de Verden; habría sido imposible en64 contrar ningún pedazo del abuelo. O sea, la pedacería era más de la necesaria, pero a quién pertenecían esas partes del cuerpo, era imposible de determinar..."

En este mismo estilo Limonov pinta la imagen de la Gran Época, expresión que usa, por supuesto, con ironía, pero ironía para quienes hubieran querido corregir tal definición. En la imagen de la Gran Época -el tiempo miserable, ascético, semihambriento y semidesnudo pero a la vez, el tiempo importante para el mundo y el país con sus hombres rígidos pero justos-el autor ve muchos cosas imponentes, le impresiona hasta la crueldad de esta época. Y esta imagen se mantiene no sólo por pinceladas impresionistas de la vida y de los tipos sociales, sino también por su fundamento ideológico: esto es, el pueblo torpe y rebelde y el César férreo por encima de él. César era sabio y duro. "No era tan fácil obligar a los militares armados que habían atravesado la mitad de la Europa a convertirse de nuevo en sumisos y pacíficos... el bandidaje armado había sido... un fenómeno normal. Precisamente por eso Stalin introdujo la pena de muerte en 1949 ... Con gran dificultad a mediados 
de los años cincuenta, estrechando más y más la libertad de los soldados, éstos volvieron a la sumisión que existía antes de la guerra."

¿Pero contra quién se dirige esta ironía? Vamos a analizar su carácter porque es muy importante para la comprensión de la posición del autor. Pienso que es fácil imaginar la reacción del lector contemporáneo que hace tiempo se ha quitado las "lentes rosas" y está cansado de las palabrerías y de los discursos pronunciados con pathos y elocuencia. Tal vez este lector se quede perplejo y confuso ante aquella persona que de nuevo dice este tipo de discurso. La sublime manera de hablar no tiene credibilidad, y en tal situación sería más favorable una ligera dosis de autoironía del orador, que le disculpara de la solemnidad de su pose. Pero la ironía como tal no disminuye el pathos, sino que, al contrario, aumenta la confianza hacia el orador. La función de la autoironía de Limonov tiene precisamente este objetivo. $Y$ de hecho, a pesar de su juego travieso con los sentidos y de su ironía permanente, Hemos tenido la Gran Época, está imbuida de pathos, que es el pathos del hijo pródigo, quien se sublevó contra sus padres y a fin de cuentas les abandonó; quien tuvo opiniones opuestas en cuanto a la familia, a la sociedad, a la política y al Estado. Sin embargo, con el tiempo, el narrador toma conciencia de que él no es sólo "carne de carne, sangre de sangre... de las aldeas rusas, sino también, espíritu de su espíritu". ¿Qué le enseñaron sus padres? "Lo mismo que le enseñan a los niños los campesinos de Borgoña, Rhin o los farmers del Mississippi". Es el medio seguro de conquistar las simpatías del lector y en particular del lector occidental, que sobrevivió al retorno de la "juventud rebelde" a la casa de sus padres. Y después podrá jugar con el lector conquistado por diferentes maneras extravagantes; por ejemplo, dar un retrato correspondiente de Stalin o resucitar la moral sancionada por aquella ideología estatal, reírse ligeramente de la seriedad e intransigencia del lector nacional y mofarse de la confianza ingenua de los lectores occidentales que creyeron en Dombrovski y Shalamov. Podrá incluso ironizar sobre el propio papel del cantante de la Gran Época, pero hasta ciertos límites. El papel del hijo pródigo que regresa a su hogar paterno impone obligaciones. "Este libro es mi variante de la Gran Época; mi visión de ésta. Yo le abrí paso a través de debatir los puntos de vista que otros quisieron imponerme. Estoy seguro en mi visión."

¿Es libre Limonov? Sí, lo es, desde luego desde nuestros cánones y prohibiciones. Él rechazó tradiciones de la literatura rusa "terriblemente 
serias y penosas" (según su propia expresión). Él puede permitirse a sí mismo todo, pero...hasta cierto punto. Los límites están marcados claramente: es la necesidad de verse a sí mismo en el espejo de la prensa: "¿cuál es mi imagen? ¿todavía tengo éxito? ¿aún soy vendible?"

El análisis tan detallado del libro de Limonov se justifica porque dicha modificación de la esclavitud interior es un fenómeno relativamente nuevo en nuestra literatura. Por otra parte, el proceso de comercialización de la literatura artística difundido hoy en día puede hacer mucho mayor tal tipo de esclavitud.

Vajtin, en la novela Una aldea absolutamente feliz (Neva, 1989), da su propia variante de la Gran Época difundida por toda la vida aldeana de Rusia. La historia es contada por los protagonistas de la narración -Mijeev y Polina - en diversos acontecimientos: la boda en vísperas de la guerra, la muerte de Mijeev, el orfanato de sus hijos gemelos, la vida difícil de la viuda aldeana. La libertad artística de Vajtin en el manejo de este material no consiste en que lo somete a su idea, sino, al contrario, en que aspira a entrar al fondo, a encontrar lo que mantiene a estas vidas, lo que les motiva; lo que le hace vivir y trabajar a Polina, agotada por completo de tal existencia difícil y lo que da fuerzas a esta aldea para sobrevivir.

En el origen de esta fuerza están el mismo amor y el honor, la compasión y el autosacrificio. En la novela, escrita de manera muy peculiar (parecida en este sentido a la canción rusa antigua ejecutada en diferentes voces: tristes, joviales, nostálgicas y alegres), el autor logra mostrar lo esencial de estos conceptos: la naturaleza de la fuerza que vive en Polina, en Mijeev y en un anciano filósofo aldeano. Vajtin ve la relación directa entre el ser moral de sus personajes y el torbellino natural de las cosas y fenómenos, y refuta demostrativamente ciertas motivaciones familiares en una escena que es muy característica para nuestra literatura. Por la mañana, después 'de su boda, Mijeev, al enterarse que empezó la guerra se dispone a preparar su mochila. "Has leído muchos periódicos... -reprocha Polina a su joven marido- y quieres ser el primero..." "Te juro que no he leído estos periódicos... No quiero llegar a ser héroe por allá..." Simplemente ocurrió la desdicha y por eso es necesario enfrentarla más rápido para luego vivir, trabajar en la agricultura y amar a su esposa; "por eso me apuro ahora para participar en el asunto militar y acabarlo más rápido y volver a ti y entonces, nadie podrá molestarnos y vamos a vivir como hemos querido y hasta mucho mejor, porque nos extrañaremos mucho, ahora yo ya empiezo a extrañarte". 


\section{PERESTROIKA DE LA LITERATURA}

El mundo que crea Vajtin está lejos de categorías abstractas, más exactamente, estas categorías se comprueban en ese mundo por la verdad natural de la vida. Propiamente hablando, los personajes están ocupados en entender lo que les ocurre y vincularlo en algún sistema de comprensión. Los pensamientos viven en ellos, afirma Vajtin, "simples... parecidos a las raíces de los árboles que no están enmarañadas porque no existen raíces enmarañadas, las ideas se enmarañan sólo en el hombre inculto, las raíces del árbol no se enmarañan... se prenden discretamente en la profundidad necesaria y se extienden también, según su necesidad..."

El arte crea su propia realidad, en esto consiste su predestinación, como el vino, que al terminar de fermentarse, elimina de la uva, su materia prima, otras propiedades, pero precisamente en su calidad nueva es capaz de conservar la energía de la uva. La actitud que presupone únicamente la "resistencia" y el comentario irónico ahora pierde su encanto. Las obras que tienen actitudes más positivas y creativas son las que pueden desarrollarse en el nuevo espacio literario de nuestro tiempo.

En nuestra crítica se consolidó un estereotipo del escritor underground, necesariamente rebelde, nihilista, cuestionador de los propios fundamentos de las tradiciones literarias. Y sin embargo, la obra de Yuri Karabchievski, uno de los más destacados escritores underground de ayer, no tiene nada que ver con este estereotipo. Este escritor es tradicional en todo: en su manera narrativa, en la elección de los temas, en su parca actitud ante la palabra (morbosa y a la vez exigente), en su aspiración a la exactitud y al ahorro de los medios para la expresión de los matices de pensamientos y sentimientos. En la técnica de su prosa se siente la escuela de los maestros de los años veinte-treinta, y por su contenido ético es continuación de las tradiciones de la literatura rusa del siglo XIX. Testimonio de esto es su novela La añoranza por Armenia que continúa la tradición de la literatura rusa del siglo $\mathrm{XX}$, representada por los nombres de Mandelshtam y Bitov. La narración se concentra en el tema de la casa. Casa de los armenios, casa de los rusos, y casa en general, que es el tema orgánico para Karabchievski, con una actitud más o menos optimista frente a nuestra historia. Y sin embargo, en algún lugar muy profundo de su alma él guarda la imagen de la chimenea helada que se eleva sobre los restos carbonizados de una casa, que es la imagen del siglo XX, impregnada por el olor recio de la quemazón, del vagabundeo, de la vida nómada y la desdicha. Pero al llegar a Armenia y ver los 
rasgos contemporáneos de su cultura, el autor percibirá (a pesar del intenso viento que soplaba en el territorio, nuestra unión inquebrantable durante los últimos decenios) el calor del hogar nacional, del pueblo, cerca del cual pueden calentarse tanto los dueños como los huéspedes. Quizás, no es propiamente el calor del hogar nacional, sino la nostalgia de éste lo que le conmovió, ya que los valores que heredamos de la experiencia pasada nos son primordiales...

¿Por qué la prosa de este escritor, que tiene reputación de "rebelde" (en virtud de su libro talentoso y en realidad tradicional y humano, $L a$ resurrección de Mayakovski), igual que la de Veniamin Erofeev (o Sacha Sokolov, o Boris Vajtin) se califican de modernistas y de vanguardia, que destruyen la base de la sociedad? Parecería que del underground de ayer todavía sólo se espera este papel revoltoso. Tal actitud ante la literatura presupone que el artista libre sólo dispone de la libertad de servir a las necesidades de su tiempo, ser comentarista de su época y nada más.

Pero hoy existe la esperanza de que la aureola de la pertenencia al underground se está evaporando y que junto con ella se desvanecerá la imagen unidimensional y trillada del "luchador de la palabra libre". Nuestra literatura va a retomar su propio destino, a saber: la comprensión del ser humano.

68 Muchos escritores ingresaron al underground (el término ruso es podpolie y significa clandestinidad), entre otros motivos, por la imposibilidad de ser publicados a causa de la censura vigente.

Existieron diferentes razones para no publicar. Por ejemplo, los cuentos del debutante O. Ermakov (Znamia, 1989), que en su forma y contenido son de buena calidad, apenas aparecieron hace dos o tres años porque contienen ciertas denuncias sobre la guerra en Afganistán. Por episodios como el del cuento El Bautizo, donde un soldado ruso mata a un afgano cautivo con un golpe de karate y por la descripción de la atmósfera de las crueles interrelaciones informales entre los mismos soldados, estos escritos no podían ser publicados sino hasta recientemente.

¿Quiere esto decir que los Cuentos afganos de O. Ermakovy O. Jandus (Ural, 1988), la novela de S. Kaledin, Batallón de construcción, ${ }^{3}$ (Novii Mir, 1989), que trata de las relaciones tensas entre los soldados de las

${ }^{3}$ Unidad militar integrada por quienes no podían realizar el servicio militar normal por razones de salud. 


\section{PERESTROIKA DE LA LITERATURA}

fuerzas armadas en tiempo de paz, el cuento Paisanos de A. Shabanov (Rodnik, 1989), la novela de Y. Iakimainen Las maniobras "Occidente" (Raduga de Tallinn, 1989), etc., hubieran podido ser hace algunos años de "otra" prosa? Por supuesto que no. Y esto muestra, entre otras cosas, la interrelación entre la "otra" prosa y la de la "época de glasnost".

La apertura, la censura, etc., son circunstancias que existen fuera de la literatura. La "otra" prosa impugna algo más profundo y no entraba en el conflicto con la censura, sino que elegía caminos de existencia fuera de ésta: samizdat (edición clandestina) o tamizdat (edición en el extranjero). El obstáculo principal en el camino de la "otra" prosa no fue la institución de la censura como tal, sino la de la opinión pública.

A los autores de la "otra" prosa les vincula la prosa de los "informales" de ayer, la "siembra espontánea" de la literatura. Al formarse y afirmarse fuera del proceso oficial, en condiciones de prohibición, la "otra" prosa elaboró sus características propias: "insumisión", oposición contra todo lo que le parecía oficial (y oficial para ella era casi todo lo que se publicaba...). De ahí el carácter de adolescente difícil de nuestra literatura, la dificultad de su diálogo con el lector educado en otros modelos y la misma otredad.

Es necesario caracterizar algunas figuras, sin las cuales la conversación sobre la "otra" prosa no tendría sentido. Son escritores casi desconocidos para un amplio sector de lectores de su patria, ya que todo lo que ellos escribieron se publicó en el extranjero.

Hoy nosotros tenemos la posibilidad de leer La escuela para estúpidos y Entre el perro y el lobo de Sacha Sokolov, y podemos entender porqué estos libros no tuvieron oportunidad de aparecer en nuestras revistas. La escuela para estúpidos, que el mismo V. Nabokov caracterizó como un libro conmovedor, es, según mi opinión, el libro más encantador para lectores rusos. En él se narra sobre la infancia, el primer amor, y justamente por eso es una obra muy tradicional.

Lo mismo, a pesar del modernismo del estilo, puede decirse sobre la segunda novela de Sacha Sokolov. No hay nada faccioso en estos libros, pero a los redactores indudablemente les hubiera asustado lo insólito de su escritura, y quién sabe qué suerte hubiera tenido como escritor si no hubiese publicado oportunamente sus libros. A la pregunta: cómo se encontraron en el underground algunos escritores, en el caso de Sacha 
Nadeszda Markova

Sokolov habría que responder que entró a éste bajo la máscara de la "otra orilla".

Yo creo que sería oportuna la siguiente definición de la "otra" prosa: es la literatura que reconoce y toma conciencia de sí misma sólo y tan sólo como un fenómeno de la lengua. Esta autopercepción determina su tendencia principal: la actitud de "lo debido" ante "lo real", algo análogo a la fracción sin numerador. Lo real está presente de modo palpable y evidente..., lo debido está escrito en la arena, todos las exhortaciones son sólo palabras, palabras, palabras que no tienen ninguna fuerza.

El autor - personaje- de la novela de Evguenii Popov El alma del patriota o diferentes epístolas a Ferfichkin (Volga, 1989) discurre: “...Es una tontería, Ferfichkin, que la ideología tome a la literatura en serio... ¿por qué se conserva esta mala tradición? Que el payaso baile al son que le tocan. El payaso es peligroso sólo cuando ustedes le prestan atención considerándole como una fuerza real. Mientras que, en realidad, él es débil. Es decir, no se excluye que detrás de él vaya el coro seducido por su canto impúdico, pero teóricamente es tan poco posible y prácticamente es tan raro, que no vale la pena prestar tanta atención a estos santurrones..." En este fragmento se muestra una baja evaluación del papel del artista (El payaso, Flauta tonta) y se expresa duda en la impresión positiva del lector que está "más allá de la página".

En su tratamiento de la literatura como fenómeno exclusivamente lingüístico, la "otra" prosa está muy cerca de la famosa opinión de V. Nabokov (su ensayo Nicolai Gogol se puede considerar como "el premanifiesto" de los "otros" prosistas). Se acercan, también desde el punto de vista de Nabokov, las complicadas relaciones de autor-lector que frecuentemente llegan al conflicto y conducen a la violación del diálogo. Pero hay diferencias: a la "otra" prosa no le es propio el dandismo ${ }^{4}$ altivo; la actitud de esta prosa hacia el lector no está por encima, sino al lado de él, en el mismo nivel aunque aisladamente, como un vecino en el vagón del metro.

La imposibilidad de influir directamente sobre la vida es capaz de inspirar un sentimiento pesimista. La "otra" prosa es frecuentemente fúnebre. Los cuentos de Anatoli Gavrilov (Volga, Unost, Enicei) son depresivos y "sin salida". Nadie entiende a sus protagonistas: el cerrajero

${ }^{4}$ dandy: caballero aristócrata. 


\section{PERESTROIKA DE LA LITERATURA}

del "servicio del gas líquido" se confiesa ante su maletín de instrumentos (Maletín); el estudiante que elabora las "leyes jurídicas para el espacio cósmico" padece la burla de su hermano (En vísperas de la vida nueva); las esperanzas de felicidad de una muchacha fea llamada Rosa, salir de su fastidioso medio, son posibles sólo en el sueño (Rosa). Los personajes de los cuentos de Gavrilov nunca pueden ponerse de acuerdo con el mundo, la palabra encuentra su debilidad y de esta manera el humor pesimista de los personajes contagia a su autor.

El sentimiento de impotencia de la palabra, desde luego no fue experimentado por primera vez por los "otros" prosistas. Tradicionalmente, este sentimiento fue expresado como culpabilidad de la literatura ante la vida. En Rusia era incómodo y hasta vergonzoso ser simplemente escritor. La obra se consideraba como vacía, mentirosa, absurda, si no se encontraba otra justificación de sí misma, su "punto de aplicación". ("Se quería llevar a cabo cualquier función en la tierra pero no había ningún punto de aplicación", se lamenta el protagonista de Eugueni Popov.) Según la gran tradición nacional, la justificación se encuentra al servicio de un asunto público, a la promesa o a la hazaña en aras de alguna gran idea por encima de la literatura, la idea positiva dirigida a un futuro hermoso y radiante. La fe, la esperanza y el amor señalan e iluminan el camino y la literatura clásica nacional comprende su tarea como un llamamiento a consolidarse y seguir por él.

La misma idea de que la literatura nacional pudiera desviarse del “camino magistral" se reprueba de antemano. En esta posible desviación se ve un peligro destructivo, y tal opinión tiene algo de razón.

En cuanto a la desviación de la "otra" prosa del camino magistral de la tradición nacional, conviene decir que uno frecuentemente no se percata sobre el hecho de que ya en el inicio de nuestro siglo surgió la nueva literatura rusa, a la cual, como regla, se orienta la "otra" prosa. Como sus antecedentes, la "otra" prosa se da cuenta que difundir optimismo en los corazones sólo significa producir un "sueño dorado en la humanidad". Al final de nuestro siglo es imposible creer en la fe positivista del progreso, que es capaz de hacer feliz a la humanidad y resolver todos los problemas. ¿De esto, quédeducciones hace para sí el "otro" prosista? Él es un hombre informado, le es difícil olvidar que ni las prédicas de Dostovievski, ni los sermones de Tolstoi, ni el llamado a la armonía de Pushkin, ni siquiera toda la Literatura o la palabra como 
tal, pudieron salvar al pueblo, al país, de los golpes trágicos de la Historia. Por lo mismo, cierta dosis de escepticismo en la literatura contemporánea, dirigida a sí misma, no resulta gratuito. Tal vez parezca imposible preferirlo, pero sí se puede y se debe comprender.

La "otra" prosa no está inclinada a considerarse como organizadora y difusora colectiva, portavoz y portadora de ideas. De aquí proviene su rechazo a cualquier imperativo y el carácter extravagante de su diálogo con el lector. La conversación tiene sentido, sí, pero un sentido condicional, sólo en un pequeño círculo, En su círculo (el nombre del cuento de L. Petruschevskaya) donde "nadie discute con nadie de nada. Nadie está de acuerdo con nadie, ¿en qué? Es igual, no importa..." (E. Popov).

¿Y qué se descubre? Se descubre que la literatura (y más ampliamente, la cultura) a pesar de todas las divergencias y discusiones, en el pasado estuvo unida mientras que hoy está en camino de disgregarse en diferentes subculturas; cada vez más aflora su carácter multifacético y contradictorio.

¿Cuál es la relación entre la "otra" prosa y la demás literatura? Ante todo, a pesar de todas las desviaciones, este fenómeno sigue el cauce de la misma corriente de la literatura rusa. El conflicto de la "otra" prosa con la gran tradición recuerda el frecuente conflicto entre padres e hijos; en otras palabras, es un asunto familiar. Las analogías más cercanas de esta discusión se encuentran en las famosas disputas literarias de principios del siglo XX. Aquíla figura más importante para los "otros" prosistas es V.V.Rózanov. Y no se trata sólo de referencias como las de E. Popov ("El lithermano me miraba con una miradita aguda") ni de las imitaciones. El quid del asunto está en los descubrimientos de Rózanov, que no se disolvieron durante décadas. En primer lugar, la "otra" prosa imita la manera de Rózanov de conversar en primera persona. (Sería ingenuo considerar los famosos libros "de confesión" de Rózanov, Soliloquis y Las hojas caidas como apuntes de un diario.) Evgueni Popov, en su prefacio a la novela El alma del patriota... comunica que él es sólo el editor de la correspondencia de cierto literato, Eugueni Anatolievich Popov.

La principal vinculación entre muchos modelos de la "otra" prosa con la tradición de Rózanov es el espíritu ensayista que le es inherente. El pensamiento-imagen y la intervención del autor en la estructura de la obra son características de la "otra" prosa, que pone en duda cualquier 
PERESTROIKA DE LA LITERATURA

forma de imitación absoluta de la vida. Los "otros" prosistas casi nunca se plantean la tarea de la creación del mundo multicolor, multifacético, plásticamente acabado, que existiera independientemente del autor. Entre el lector y el autor siempre existe "la voz-mediadora" que induce a recordar que todo lo comunicado son "palabras, palabras, palabras", sólo literatura. Como si temiera caer en la trampa del mundo efímero de los signos, el autor no se inclina a engañar al lector. Más que eso, el arte que, según los "otros" prosistas, puede engañar, al ocultar la idea falsa detrás de formas perfectas, provoca en él desconfianza, el deseo de descubrir lo falso por medio de la parodia.

Pero hasta el esbozo de algunas figuras esenciales de nuestro tema resulta ineficiente para cualquier generalización. Para continuar con nuestro discurso será necesario tratar de encontrar un hecho literario que esté en el centro, alejado igualmente de los polos, pero que exprese las tendencias características de la "otra" prosa. Tal hecho puede ser la novela de E. Popov, El alma del patriota o diferentes epístolas a Ferfichkin.

Es una narración a través de cartas y un diario del "otro" prosista en el período "informal" de su vida; el testimonio documental, la confesión y el manifiesto literario. Nosotros podemos mirar al "otro" prosista en un contexto amplio de la vida. Al exponernos la novela de sí mismo, de su ambiente cercano y de su vida, el autor se convierte en un personaje: el compositor de las epistolas a Ferfichkin. Eugueni Anatolievich Popov es al mismo tiempo homónimo del autor, aunque asegura que es una casualidad, que "yo no soy él".

Al concederle el derecho a E. Popov de la transformación artística de la realidad vamos a partir, empero, si no de la identidad, por lo menos, de la semejanza que existe entre los acontecimientos descritos en la novela y la biografía literaria del prosista. E. Popov es uno de los "antihéroes" de un incidente ruidoso alrededor de la miscelánea Metropol, que fue el primer intento de publicar la "otra" prosa. Pero en el tiempo artístico de la novela, la miscelánea Metropol es un hecho pasado que se menciona sólo a través de alusiones y alegorías. "Una vez me asomé a este mundo abierto y me recibieron con un golpe en el hocico"; o "hemos salido del hotel con el nombre familiar de Metropol". Las epístolas a Ferfichkin tienen la fecha: septiembre-diciembre 1982, cuando el autor-personaje, al curar las viejas heridas e inspirarse en las ideas 
Nadeszda Markova

de la hermandad y del olvido de las mutuas ofensas, escribe su nueva obra "en el escritorio". El "otro" prosista no tenía esperanza de publicar en 1982, pero quería escribir; era necesario hacerlo: un día sin redactar un renglón provocaba en el autor de las epístolas a Ferfichkin remordimientos de conciencia. "Hace falta escribir hoy una hoja, por lo menos, media hoja." Él se autoimponía serias obligaciones; hacía "el contraplán", calculaba "las normas", apuntaba "los últimos" plazos de entrega para su producción, etc. Inicialmente, no se puede entender qué prevalece: la parodia jovial o la amargura. Lo que pasa es que el autor no olvida ni un instante que él en esencia se ocupa de la "bagatela automultiplicada", ya que piensa que nadie leerá su obra, e incluso hasta prescinde del remitente en las epístolas a Ferfichkin. Este personaje no existe en sentido material, pero cada uno de los lectores y locutores imaginarios es Ferfichkin.

Según la actitud creativa, que se postula en las primeras páginas, el objeto del arte lo es todo. El autor ve su tarea en el reflejo puntual de todo lo causal y no causal que cae en su campo visual o se eleva en su memoria. "Escribo lo que quiero", declara E. Popov. A su retorno de la comisión de servicio empieza a describirle a su "querida esposa" los acontecimientos sucedidos en este viaje; cuenta, entre otras cosas, los precios en el mercado de Voronezh, relata como pasó la noche con sus amigos, etc. La alcancía de yeso, comprada casualmente, le evoca recuerdos de la alcancía de su niñez en los años de posguerra y por asociación azarosa los pensamientos del autor se dirigen al pasado; empiezan los recuerdos sobre la infancia en Siberia, las leyendas familiares, las anécdotas curiosas sobre numerosos parientes: las pintorescas "abuela Pacha" o "abuela Maricha"; las fotografías familiares son descritas con escrupulosidad de protocolo. Se describe "todo el mundo", pero prevalecen las escenas familiares; tema que el autor considera como el más importante, significativo y necesario, aunque todavía no se sabe porqué. A la pregunta: "¿para qué toca el pasado?" la contesta: "es interesante". Por ahora no queda otra opción que creer en la tesis del autor, que la vida es más rica que cualquier ficción, por eso no es necesario inventar nada: "se puede encontrar a cualquier transeúnte y preguntarle cómo ha pasado el día y de golpe escribir una novela como Ulises de Joyce".

Las primeras páginas de la novela, por una parte, arrojan al lector un montón de imágenes-hechos, de observaciones y pensamientos, hasta 
que, de repente, surge la sensación de totalidad, de unidad de la narración, y uno involuntariamente piensa: ¿cómo se mantiene todo esto, qué lo sujeta? Ante todo - y esto es lo más evidente — en la personalidad del autor.

$\mathrm{Y}$ aquí podemos formular la primera conclusión: el acercamiento entre la posición del autor y la del personaje no consiste en que el autor sólo sea capaz de hablar de su propia persona y carezca de habilidad para expresarse sobre otras cosas. Es un intento de apoyarse en sí mismo, en su propia experiencia, en su sentido común; es un intento de tener su propia opinión en un mundo que provoca la despersonalización del hombre. El propio "yo", el "ego", se pone en el centro de la percepción del mundo para no perder su sí mismo, "su alma viva", para no convertirse en juguete de la voluntad ajena, de palabras, juicios y opiniones de otros.

Este peligro es real; el autor-personaje se encuentra en circunstancias precarias, en primer lugar, en sus relaciones con los editores. Evgueni Anatoiievich tiene plena razón al vincular sus desbarajustes literarios no tanto con redactores concretos que "exhalan las fragancias francesas y las neblinas rusas", como con la sensación común de "no fraternidad" (término de N.F. Fiodorov): cuando cada uno te mira enfadado "como a un enemigo" se tienen ganas de huir de este mundo ajeno y hostil y dirigirse al pasado. En la novela todo el mundo se divide en un presente frío, enajenado, y en un pasado sincero, calentado por el afecto a las personas queridas, pintadas, aunque sin una estimación excesiva, con verdaderos sentimientos.

La vivencia de esta ruptura es el sentimiento principal de la novela que, en su esencia, es el diario del hombre perdido en el presente y que, sin culpa, no logra socializarse. En la vida conocemos una multitud de casos semejantes que terminan a menudo trágicamente: por el enfurecimiento del hombre marginado, por su ruptura definitiva con la sociedad o en el ensimismamiento. El autor-personaje de El alma del patriota... no perdió la capacidad de dialogar y, quizás, esto es más significativo en sus epístolas dirigidas al mundo.

De repente la marcha de la narración cambia bruscamente con una nota fechada un día de noviembre de 1982. "iMurió él, quién era...!", dice emotivamente el narrador, y nosotros recordamos bien de quién se trata... La segunda mitad de la novela describe "los vagabundeos fúnebres" por las calles de Moscú del autor-personaje en compañía del "otro" 
Nadeszda Markova

literato (el poeta conceptualista y pintor Dimitri Alexandrovich Prigov). Compañeros de viaje, vagan por el Moscú otoñal al escuchar, como escribe E. Popov, "la música de la Historia".

La descripción de estos vagabundeos narrados en tono irónico ¿es el intento de convertir un acontecimiento triste (la muerte) en el mismo "objeto de arte"? Me parece que no hay razón para consideralo así. En la novela irrumpe el tiempo, el cambio de época; el autor-personaje está emocionado aunque intente esconder sus sentimientos. "Y el entusiasmo beato por la historicidad calentaba el alma del patriota que intentaba ocultarlo detrás de una bravata fingida." Si antes hemos interpretado el texto de cualquier manera al considerarlo como un chasco, una burla oculta bajo una seriedad fingida o enmascarada, ahora esto ya no tiene importancia: comienza la conversación sobre lo esencial y los matices en la entonación del autor pasan a segundo plano. E. Popov inquieta al lector por las infinitas digresiones del sujeto. Al vagar con su compañero en los días fúnebres por las calles de Moscú, con escrupulosidad de guía no pierde la ocasión de comunicar quién y cuándo construyó uno u otro edificio y, más que eso, con qué recuerdos del autor están vinculados. Parece que el prosista menosprecia el acontecimiento, cada vez trata de otras cosas ("no importa", "otra cosa", son palabras importantes de la

76 prosa de E. Popov; justamente uno de sus cuentos se llama $\mathrm{No}$, es otra cosa...) y sin embargo, el lector siente que a nivel general esta manera paradójica crea la verdadera perspectiva histórica de la narración. El autor nos remite a los siglos pasados (y lo hace frecuentemente de manera denominativa: "los bulevares de circunvalación surgidos en el lugar de la pared demolida de la Ciudad Blanca... Oh, Arbat, "mi arbat"" (suburbio árabe), etc. $O$ de repente el autor dedica mucho espacio - con evidente placer - a su amigo de la juventud estudiantil, Serguei P., a quien introduce en la narración "aprovechando la posición oficial de autor", porque "siempre fue amable conmigo". Estas, a primera vista, desviaciones paradójicas del tema, el carácter travieso del narrador y todas sus "excentricidades vanguardistas" introducen en la narración sobre los días importantes en la historia del país, un sentimiento íntimo y a la vez extraño. La esperanza de los cambios, del surgimiento de algo nuevo —quizás, las cosas irán de otro modo dice un personaje de El alma del Patriota... - están invisiblemente presentes en un rincón de la conciencia del autor-personaje, aunque él aparta (¿a causa de la supersti- 
ción, quizás?) este pensamiento inculcándose la idea de que se siente cómodo en el calor de su casa, detrás de las cortinas. Por supuesto, nosotros sentimos que él, como gato escaldado que huye del agua fría, simplemente teme creer, teme conjurar el "mal de ojo" a sus propias esperanzas y las de los otros en que ahora la vida será otra: más justa, más racional, más fraternal... A despecho de su ironía, el autor empieza a hablar seriamente; y una cadena que puede parecer indecente - "yo quiero pastel, yo quiero a mi esposa, yo quiero a mi Patria" - ya no es tal.

Partiendo de la negación total y la burla sobre todo, E. Popov llega a algo positivo: a la exhortación de la fraternidad, al perdón de las ofensas, al olvido de las discordias y a la afirmación - como si no pareciera grandilocuente - del ideal de la vida. A pesar del carácter utópico del futuro, que provoca la sonrisa de los lectores (todos van a andar con "camisas limpias" y ya no habrá intrigas), no olvidemos que la literatura nacional es incomprensible sin tal quijotismo e inocencia.

Al comprenderlo, uno empieza a dudar: ¿E.Popov es modernista? Es modernista sólo desde el punto de vista de los defensores de los cánones literarios. Pero, en realidad ¿la "otra" prosa es tan otra? Al absorber casi todos los rasgos propios del posmodernismo, El alma del Patriota... en su propio espacio artístico es la negación de éste, ya que lo supera sometiendo sus métodos a prueba; y a esto lo percibe un lector imparcial. No es ya la "otra" prosa, sino la prosa contemporánea que se da cuenta que cualquier carácter declarativo y categórico de los juicios ya no funciona, al igual que la moraleja didáctica, y que con el lector contemporáneo es necesario hablar con otro tono.

Al separar su "ideal positivo" del contexto artístico, sería una exageración decir que esta novela es tan optimista como podría parecer. Por supuesto que a lo que exhorta el autor, lo que vislumbra al "final del túnel” no se dará por sí mismo. Las fuerzas contrapuestas están claramente perfiladas. Pero la búsqueda del camino por el intelecto y el corazón inspira esperanzas de que los autores de la "otra" prosa están abiertos al diálogo con la literatura y con la sociedad.

La "otra" prosa rechaza cualquier "exhortación", pone en tela de juicio el poder de la palabra y el derecho del arte de moralizar y enseñar. Pero esta duda no debe ser absoluta, la imposibilidad total de "afirmar claalquier cosa significa su propia negación” (P.A. Florenski). La elaboración de un contenido positivo es el punto que determina la existencia 
Nadeszda Markova

futura de la "otra" prosa (como, entre otras cosas, de todo el arte contemporáneo). Lo que es posible realizar lo muestra la novela de E. Popov, que dirige su ironía hacia sí mismo, a su "otredad". Por supuesto, esto es sólo una de las variantes; todavía no conocemos las otras.

En la transición del underground a la "otra", a la prosa le esperan, quizás, las pruebas más difíciles. Hasta ahora ella ha sacado su energía interior del rechazo permanente a la literatura socializada. Pero, ¿qué va a rechazar ahora, cuando está entrando en un contexto literario común, convirtiéndose en una de sus partes? ¿Qué fuerzas van a dirigirla: centrípetas o centrífugas? La continuación del antagonismo le amenaza con conflictos destructivos. Está trazada también la vía alternativa: la “otra" prosa podrá extraer su energía de la contraposición: "todas las fuerzas liberadoras en la resistencia común contra la oscuridad, contra el diablo, contra la entropía y contra la nada" (E. Popov).

Pero esto ya es exhortación, por lo cual no parece que fuera la "otra" prosa... 